\title{
Comparisons of Metabolism of Apolipoprotein B in Normal Subjects, Obese Patients, and Patients with Coronary Heart Disease
}

\author{
Y. Antero Kesäniemi, William F. Beltz, and Scott M. Grundy \\ Veterans Administration Medical Center, University of California, San Diego, San Diego, California 92161; \\ Center for Human Nutrition, University of Texas Health Science Center, Dallas, Texas 75235
}

\begin{abstract}
This study was designed to examine the integrated metabolism of apolipoprotein B (apo B) in very low density lipoproteins (VLDL), intermediate density lipoproteins (IDL), and low density lipoproteins (LDL) in normal subjects, obese patients, and a group of patients with coronary heart disease (CHD). Turnover rates of ${ }^{131}$ I-VLDL-B, ${ }^{131}$ I-IDL-B, ${ }^{125}$ I-LDL-B, and $\left[^{3}\right.$ H]VLDL-triglycerides (TG) were determined by the multicompartmental analysis that used the model described in the preceding article (Beltz, W. F., et al. 1985. J. Clin. Invest. 76: 575-585). Compared with five normal subjects, four obese subjects had increased synthesis rates of both VLDL-B and VLDL-TG. Production of LDL-B was inconsistently raised in these same patients. Five patients with $\mathrm{CHD}$ had enhanced production of both VLDL-B and LDL-B, but secretion rates of VLDL-TG were not increased. Thus, in patients with obesity and in those with CHD, synthesis rates of VLDL particles may be abnormally high. In the obese patients, the VLDL appeared to be of normal composition, but in patients with CHD, the VLDL were relatively poor in TG. The study also showed that a significant fraction of VLDL-B is removed directly from the circulation and never reaches $L D L$ regardless of the type of patients. The fraction that does reach LDL is one factor that determines LDL concentrations.
\end{abstract}

\section{Introduction}

Apolipoprotein B-100 (apo B) ${ }^{1}$ is essentially the only apoprotein of low density lipoproteins (LDL) $(1,2)$; it also is a major constituent of very low density lipoproteins (VLDL). Hepatic production rates of apo $B$ may be an important determinant of VLDL secretion rates, and the interaction of LDL-apo B with LDL receptors regulates levels of plasma LDL (3). A thorough definition of the metabolism of apo B-containing lipoproteins in the normal state, as well as in various dyslipidemias, therefore would seem necessary for an understanding of the overall metabolism of these lipoproteins.

For these reasons, the present study was undertaken to examine the integrated metabolism of apo B in VLDL and

Dr. Kesäniemi was a visiting scientist on leave from the Second Department of Medicine, University of Helsinki, Helsinki, Finland. 1985.

Received for publication 14 May 1984 and in revised form 1 May

1. Abbreviations used in this paper: apo B, apolipoprotein B; CHD, coronary heart disease; FCR, fractional catabolic rate; FH, familial hypercholesterolemia; IW, ideal weight; TG, triglycerides; TMU, tetramethylurea; VLDL-B, IDL-B, and LDL-B, very low, intermediate, and low density lipoprotein-apolipoprotein B.

The Journal of Clinical Investigation, Inc.

Volume 76, August 1985, 586-595
LDL in normal subjects, in obese subjects, and in a group of patients with coronary heart disease (CHD). Recent reports from our laboratory have shown that obese subjects (4) have increased production rates of $\mathrm{LDL}$, and the same is true for at least some patients with CHD (5). The current work extends these previous investigations to examine mechanisms responsible for enhanced production of LDL in both types of patients. It has employed techniques for the evaluation of apo $B$ metabolism described in the preceding article (6).

\section{Methods}

\section{Patients}

14 patients were studied in the Special Diagnostic and Treatment Unit of the Veterans Administration Medical Center, San Diego, California. These included five normal subjects, four obese patients, and five patients with premature CHD. The age, sex, and body habitus at the time of the metabolic studies, and diagnosis of each patient are presented in Table $\mathrm{I}$.

The five normal subjects were all men. None had a history of CHD. Their ages averaged $57 \pm 1$ yr (from 52 to $63 \mathrm{yr}$ ), and their weights were $80 \pm 1 \mathrm{~kg}(112 \pm 2 \%$ ideal weight [IW] [7]). Three subjects (nos. 2, 3, and 5) were smokers, but none had hypertension, diabetes mellitus, liver disease, or renal disease. None were taking digitalis, diuretics, or $\beta$-adrenergic blocking agents. Electrocardiograms were normal, as were their cardiovascular systems by physical examination. None were or had been on lipid-lowering diets or drugs. Plasma lipid and lipoprotein levels were below the 95th percentile for the corresponding age and sex group according to data of the Lipid Research Clinics Program Prevalence Study $(8,9)$.

The four obese patients were $54 \pm 5 \mathrm{yr}$ old (range 41 to $64 \mathrm{yr}$ ); one (no. 8) was a woman. Their mean body weight was $96 \pm 12 \mathrm{~kg}$. Each subject had a weight exceeding $125 \%$ of their ideal weight (assuming a medium body frame [7]). The percentage of IWs averaged $146 \pm 15 \%$ (range 127-189\%). None had xanthomata, xanthalasma, or fasting or 2-h postprandial hyperglycemia. Three subjects (nos. 6, 7, and 8) were smokers. None had a history of hypertension, myocardial infarction, or hepatic or renal disease, and their electrocardiograms and cardiovascular systems were normal by physical examination. None had been on any special diet or lipid-lowering drugs. All but one (no. 8) had plasma lipid and lipoprotein levels below the 95th percentile for their age and sex $(8,9)$ (Table II).

The five patients with CHD were 59 $\pm 2 \mathrm{yr}$ old (52-62 yr), and their ages at the clinical onset of CHD averaged $50 \pm 3$ yr (from 42 to $60 \mathrm{yr}$ ). Mean body weight was $73 \pm 2 \mathrm{~kg}$ (mean \% IW $=109 \pm 3 \%$ ). In three patients (nos. 10,12, and 13), coronary artery bypass grafting was done at the age of 61,50 , and $60 \mathrm{yr}$, respectively. Patient 11 had a myocardial infarction proven by electrocardiogram and enzyme changes at age 49 yr. Patient 14 developed angina pectoris at age 42 $\mathrm{yr}$, and coronary angiogram at that age revealed advanced coronary artherosclerosis. Several patients had bruits over carotid and femoral arteries, but none had heart failure. Also, none had xanthomata, xanthalasma, fasting or 2-h postprandial hyperglycemia. Two patients (nos. 11 and 14) were taking propranolol and another (no. 12) metoprolol for ischemic heart disease; three (nos. 11, 12, and 13) were on diuretics. All patients were normotensive at the time of the study. Most were smokers before their first myocardial infarction but had 
Table I. Clinical Data

\begin{tabular}{|c|c|c|c|c|c|}
\hline \multirow[t]{2}{*}{ Patients } & \multirow{2}{*}{$\frac{\text { Age }}{y r}$} & \multirow[t]{2}{*}{ Sex } & \multirow{2}{*}{$\begin{array}{l}\text { Weight } \\
k g\end{array}$} & \multicolumn{2}{|c|}{ Ideal body weight } \\
\hline & & & & kg & $\%$ \\
\hline \multicolumn{6}{|l|}{ Normal subjects } \\
\hline 1 & 52 & $\mathbf{M}$ & 78 & 68 & 115 \\
\hline 2 & 61 & $\mathbf{M}$ & 68 & 76 & 112 \\
\hline 3 & 55 & $\mathbf{M}$ & 80 & 69 & 116 \\
\hline 4 & 63 & $\mathbf{M}$ & 78 & 73 & 107 \\
\hline 5 & 54 & $\mathbf{M}$ & 78 & 70 & 112 \\
\hline Mean \pm SEM & $57 \pm 2$ & & $80 \pm 1$ & $71 \pm 1$ & $112 \pm 2$ \\
\hline \multicolumn{6}{|l|}{ Obese subjects } \\
\hline 6 & 41 & $\mathbf{M}$ & 108 & 84 & 128 \\
\hline 7 & 50 & $\mathbf{M}$ & 81 & 64 & 127 \\
\hline 8 & 61 & $\mathbf{F}$ & 71 & 51 & 138 \\
\hline 9 & 64 & $\mathbf{M}$ & 125 & 68 & 189 \\
\hline Mean \pm SEM & $54 \pm 5$ & & $96 \pm 12$ & $67 \pm 7$ & $146 \pm 15$ \\
\hline \multicolumn{6}{|l|}{ CHD patients } \\
\hline 10 & 62 & $\mathbf{M}$ & 66 & 60 & 110 \\
\hline 11 & 61 & $\mathbf{M}$ & 80 & 70 & 114 \\
\hline 12 & 52 & $\mathbf{M}$ & 70 & 64 & 110 \\
\hline 13 & 61 & $\mathbf{M}$ & 75 & 76 & 99 \\
\hline 14 & 57 & $\mathbf{M}$ & 74 & 65 & 113 \\
\hline Mean \pm SEM & $59 \pm 2$ & & $73 \pm 2$ & $67 \pm 3$ & $109 \pm 3$ \\
\hline
\end{tabular}

stopped or greatly reduced smoking after their attacks. None were on lipid-lowering drugs at the time of study. Patient 14 previously had been on cholestyramine and clofibrate, but stopped these drugs 6 mo before admission. The patients' dietary habits before admission were reviewed carefully. One patient (no. 12) claimed that he attempted to

Table II. Plasma Lipids and Lipoproteins

\begin{tabular}{cllll}
\hline & $\begin{array}{l}\text { Total } \\
\text { cholesterol }\end{array}$ & Total TG & $\begin{array}{l}\text { LDL } \\
\text { cholesterol }\end{array}$ & $\begin{array}{l}\text { HDL } \\
\text { cholesterol }\end{array}$ \\
\hline & & \multicolumn{2}{c}{$m g / d l \pm S D^{*}$} & \\
Normal subjects & & & & \\
1 & $161 \pm 5$ & $72 \pm 6$ & $101 \pm 6$ & $47 \pm 1$ \\
2 & $169 \pm 4$ & $106 \pm 3$ & $123 \pm 4$ & $30 \pm 1$ \\
3 & $195 \pm 7$ & $148 \pm 8$ & $135 \pm 4$ & $34 \pm 2$ \\
4 & $245 \pm 3$ & $133 \pm 19$ & $161 \pm 4$ & $61 \pm 1$ \\
5 & $273 \pm 6$ & $200 \pm 5$ & $184 \pm 7$ & $52 \pm 2$ \\
Mean \pm SEM & $208 \pm 19$ & $132 \pm 19$ & $141 \pm 13$ & $45 \pm 5$ \\
Obese subjects & & & & \\
6 & $207 \pm 7$ & $170 \pm 21$ & $125 \pm 5$ & $51 \pm 3$ \\
7 & $238 \pm 4$ & $130 \pm 5$ & $176 \pm 4$ & $41 \pm 2$ \\
8 & $309 \pm 10$ & $207 \pm 11$ & $218 \pm 8$ & $55 \pm 3$ \\
9 & $269 \pm 4$ & $214 \pm 10$ & $191 \pm 6$ & $36 \pm 2$ \\
Mean \pm SEM & $255 \pm 19$ & $180 \pm 17$ & $177 \pm 17$ & $46 \pm 4$ \\
CHD patients & & & & \\
10 & $191 \pm 7$ & $225 \pm 24$ & $102 \pm 9$ & $32 \pm 3$ \\
11 & $194 \pm 7$ & $109 \pm 5$ & $130 \pm 6$ & $35 \pm 2$ \\
12 & $210 \pm 4$ & $168 \pm 14$ & $129 \pm 7$ & $41 \pm 1$ \\
13 & $211 \pm 7$ & $125 \pm 12$ & $121 \pm 13$ & $45 \pm 4$ \\
14 & $332 \pm 5$ & $167 \pm 5$ & $231 \pm 5$ & $61 \pm 2$ \\
Mean \pm SEM & $228 \pm 26$ & $159 \pm 22$ & $143 \pm 23$ & $43 \pm 5$ \\
\hline
\end{tabular}

* Mean \pm SD of 18 samples during VLDL turnover study. decrease his cholesterol intake after heart surgery. None of the others were on special diets: most had been told that dietary change was not necessary because of normal plasma cholesterol. All but one (no. 14) had plasma lipid and lipoprotein levels below the 95th percentile for their age and sex $(8,9)$.

The investigations were approved by the Institutional Review Board, and all patients gave informed consent for the study.

\section{Experimental design}

During hospitalization, turnover rates of VLDL-apo B (VLDL-B), IDL-B, LDL-B, and VLDL-triglycerides (TG) were estimated. Patients were hospitalized on the metabolic ward for $10 \mathrm{~d}$ to $2 \mathrm{wk}$ before initiation of turnover studies. During this period they were fed a diet of mixed solid food and liquid formula containing $40 \%$ of calories as fat. The basic composition and pattern of this diet have been described in detail previously (10). Three liquid meals and one meal of solid food were given each day. Calories were divided approximately equally between feedings. The liquid meals were given at 8:30 a.m., 1:00 p.m., and 7:00 p.m. They contained $15 \%$ of calories as milk protein, $45 \%$ as dextrose, and $40 \%$ as fat, mostly as lard. This liquid diet was prepared by Hospital Diet Products, Organon Inc., Buena Park, CA. One meal of solid food was given at 11:00 a.m., and it contained dry cereal (corn flakes), nonfat bread, skim milk, added fat, and sugar for coffee. Fat comprised $\sim 40 \%$ of calories in the solid food meal. Cholesterol intakes ranged from 85 to $253 \mathrm{mg} / \mathrm{d}$. The ratio of polyunsaturated to saturated fats was 0.2 . Vitamin and mineral supplements were given daily. Each patient was weighed daily, and caloric intake was adjusted to maintain total body weight at a constant level throughout the study period.

The following design was used for lipoprotein turnover studies. The studies required injections of exogenously labeled VLDL and LDL. Plasmapheresis was done $5 \mathrm{~d}$ before injection of labeled VLDL. VLDL was isolated by ultracentrifugation, labeled with ${ }^{131} \mathrm{I}$, and prepared for injection. For $36 \mathrm{~h}$ before injection, the patients were fed a fat-free diet containing $60 \%$ of calories required for weight maintenance. They were then injected simultaneously with ${ }^{131}$ I-VLDL and $\left[2-{ }^{3} \mathrm{H}\right] \mathrm{glycerol}$. They were continued on the fat-free diet for another $48 \mathrm{~h}$, and blood samples were obtained frequently during this period. On each plasma sample, total lipids were measured, and VLDL, IDL, and LDL were isolated by preparative ultracentrifugation. On whole plasma and each lipoprotein fraction, radioactivity was counted. Apo B was estimated on each lipoprotein fraction, and its specific activity was determined. Cholesterol and TG also were measured on each sample.

On the plasma obtained at plasmapheresis, LDL also was isolated by sequential centrifugation. LDL was iodinated with ${ }^{125} \mathrm{I}$, and prepared for injection. $48 \mathrm{~h}$ after injection of ${ }^{131} \mathrm{I}-\mathrm{VLDL},{ }^{125} \mathrm{I}-\mathrm{LDL}$ was given intravenously. Blood samples were collected frequently during the 1st $\mathrm{d}$ after injection of ${ }^{125} \mathrm{I}-\mathrm{LDL}$ and then daily thereafter for $14 \mathrm{~d}$. The diet for the period after injection of ${ }^{125} \mathrm{I}-\mathrm{LDL}$ was identical to that used before the study, i.e., an isocaloric diet containing $40 \%$ of calories as fat.

From masses and radioactivity data obtained above, multicompartmental analysis of lipoprotein kinetics was carried out as described in the preceding article (6).

\section{Techniques for lipoprotein turnover studies}

Plasma lipids and lipoproteins. Concentrations of cholesterol and TG in total plasma and lipoprotein-fractions were determined on a Technicon Auto-Analyzer II (Technicon Instruments Corp., Tarrytown, NY $[11,12])$. Standardization was followed as described in the Lipid Research Clinics Manual of Laboratory Operations (13).

Lipoprotein isolation and iodination for injection. After patients had been on the metabolic diet for 10-14 d, plasmapheresis was carried out by collecting blood $(500 \mathrm{ml})$ into sterile, pyrogen-free bags containing $500 \mathrm{mg}$ of disodium EDTA. After centrifugation $\left(20^{\circ} \mathrm{C}\right)$ at $5,500 \mathrm{~g}$ for $5 \mathrm{~min}$, plasma was separated from cells, and the cells were returned to the patient. VLDL and LDL were isolated according to Lindgren et al. (14). VLDL was separated at density (d) $1.006 \mathrm{~g} / \mathrm{ml}$ in an SW-27 
swinging bucket rotor in an L2-65 B ultracentrifuge (Beckman Instruments, Inc., Spinco Div., Palo Alto, CA) at $23,000 \mathrm{rpm}\left(10^{\circ} \mathrm{C}\right)$ for 22 h. VLDL was aspirated from the top by a Pasteur pipette, mixed with sterile $\mathrm{NaCl}$ solution $(d 1.006 \mathrm{~g} / \mathrm{ml})$, and subjected to further ultracentrifugation for $22 \mathrm{~h}$ in a 40.3 Beckman rotor at $39,000 \mathrm{rpm}\left(10^{\circ} \mathrm{C}\right)$. The concentrated VLDL was then dialyzed against $0.15 \mathrm{M} \mathrm{NaCl}$ containing $0.01 \%$ EDTA (pH 7.4). After VLDL was removed after the first centrifugation, the infranatant was adjusted to $d 1.025 \mathrm{~g} / \mathrm{ml}$ with a sterile solution of $\mathrm{NaCl}-\mathrm{NaBr}$ and centrifuged in a $60 \mathrm{Ti}$ rotor at $59,000 \mathrm{rpm}\left(15^{\circ} \mathrm{C}\right)$ for $18 \mathrm{~h}$. After removal of the supernatant, the infranatant was adjusted to $d 1.060$ using $\mathrm{NaCl}-\mathrm{NaBr}$. LDL was then isolated by centrifugation at $65,000 \mathrm{rpm}$ in a 65 rotor at $15^{\circ} \mathrm{C}$ for 14 h. A final ultracentrifugation was done in a 40.3 rotor at $39,000 \mathrm{rpm}$ for $24 \mathrm{~h}\left(15^{\circ} \mathrm{C}\right)$ after overlaying the LDL with an equal volume of a $\mathrm{NaCl}-\mathrm{NaBr}$ solution of density $1.070 \mathrm{~g} / \mathrm{ml}$. The concentrated LDL was then dialyzed against $0.15 \mathrm{M} \mathrm{NaCl}$ containing $0.01 \%$ EDTA (pH 7.4).

The apoproteins of VLDL and LDL were labeled with ${ }^{131} \mathrm{I}$ and ${ }^{125}$ I, respectively, by the iodine monochloride method of McFarlane (15) as modified by Bilheimer et al. (16). The molar ratio of iodine atoms and protein was less than one. The efficiency of radiolabeling of VLDL was 6-18\% (mean 11\%) and of LDL was 9-29\% (mean $19 \%)$. The extent of lipid labeling was determined by extraction of the labeled VLDL and LDL with chloroform/methanol (2:1 vol/vol) (17). The organic phase was evaporated to dryness and radioactivity was determined in the residual lipid. The mean percentage of radioactivity in the lipid moiety of VLDL was $14 \%$ (range 8-29\%) and in LDL was $4.5 \%$ (range 3-9\%). The amount of unbound iodine after dialysis was determined by thin-layer chromatography on Gelman ITLC-SG sheets (Gelman Sciences, Inc., Ann Arbor, MI) using 20\% trichloroacetic acid containing $0.125 \%$ sodium metabisulfite. The percentage of ${ }^{131} \mathrm{I}$ and ${ }^{125}$ I not bound to the VLDL (LDL) protein averaged $0.49 \%$ for VLDL and $0.35 \%$ for $\mathrm{LDL}$.

After removal of unbound iodine by dialysis, the labeled lipoprotein preparation was subjected to centrifugation at $20,000 \mathrm{~g}$ for $30 \mathrm{~min}$ $\left(4^{\circ} \mathrm{C}\right)$; the supernatant was removed and passed through a $0.22-\mu \mathrm{m}$ Millipore filter (Millipore Corp., Bedford, MA). Sterile human serum albumin in a $5 \%$ solution was added to the ${ }^{131} \mathrm{I}-\mathrm{VLDL}$ or ${ }^{125} \mathrm{I}-\mathrm{LDL}$ to dilute the final product to a concentration of $\sim 10 \mu \mathrm{Ci} / \mathrm{ml}$. This solution was then passed again through a $0.22-\mu \mathrm{m}$ Millipore filter, and aliquots were tested for sterility and pyrogenicity.

Turnover design for VLDL-B and VLDL-TG. For $36 \mathrm{~h}$ before injection of radioactivity, the patients consumed a fat-free liquid formula every $3 \mathrm{~h}$ around the clock. The formula contained $1.25 \mathrm{cal} /$ g, $75 \%$ of which was glucose and $25 \%$ was milk protein. The liquid formula intake was calculated to provide $60 \%$ of the calories needed to maintain weight in the prestudy period. Fat was eliminated to prevent influx of chylomicrons during the study of VLDL metabolism. It was not replaced with carbohydrate to avoid carbohydrate-induced rise of plasma TG. This diet has been shown to be associated with a constant level of VLDL-TG throughout the 48-h study (18). $4 \mathrm{~d}$ after plasmapheresis and after $36 \mathrm{~h}$ on the fat-free diet, patients were injected simultaneously with $1-6 \mathrm{mg}$ of ${ }^{131} \mathrm{I}-\mathrm{VLDL}$ protein $(5-25 \mu \mathrm{Ci})$ and 300 $\mu \mathrm{Ci}$ of $\left[2-{ }^{3} \mathrm{H}\right] \mathrm{glycerol}$ (New England Nuclear, Boston, MA). Blood samples $(10 \mathrm{ml})$ were collected at $0.25,0.5,1,2,3,4,5,9,12,18,24$, $30,36,42$, and $48 \mathrm{~h}$ after injection.

Turnover design for $L D L-B$. Immediately after the $48-\mathrm{h}$ sample above, $2-10 \mathrm{mg}$ of ${ }^{125} \mathrm{I}-\mathrm{LDL}$ protein $(25-50 \mu \mathrm{Ci})$ were injected intravenously. The patients resumed the basic metabolic diet (described above). The first fat-containing meal was $\sim 3 \mathrm{~h}$ after the LDL injection. Blood samples $(10 \mathrm{ml})$ were collected at $0.25,0.5,1,6,12$, and $24 \mathrm{~h}$ and daily in the fasting state thereafter for $14 \mathrm{~d}$. Urine specimens were collected immediately after injection; complete collections were combined into 24-h pools for the next $14 \mathrm{~d}$.

Isolation of $V L D L, I D L$, and $L D L$. Determinations of total cholesterol and TG were made on each plasma sample; VLDL, IDL, and LDL were then isolated on each by sequential ultracentrifugation. 4 $\mathrm{ml}$ of each sample was centrifuged after overlaying with $2 \mathrm{ml}$ of $\mathrm{NaCl}$ $(d<1.006 \mathrm{~g} / \mathrm{ml})$ in a 40.3 rotor at $39,000 \mathrm{rpm}$ for $20 \mathrm{~h}\left(15^{\circ} \mathrm{C}\right)$. VLDL $(d<1.006 \mathrm{~g} / \mathrm{ml})$ was isolated by tube slicing $(\sim 1.5 \mathrm{ml})$. The infranatant was adjusted to a density of $1.019 \mathrm{~g} / \mathrm{ml}$ by the addition of $\mathrm{NaCl}-\mathrm{NaBr}$ and subjected again to ultracentrifugation for $20 \mathrm{~h}$ in a 40.3 rotor at $39,000 \mathrm{rpm}\left(15^{\circ} \mathrm{C}\right)$. IDL was isolated by tube slicing $(\sim 1.0 \mathrm{ml})$ and dialyzed to $d 1.006 \mathrm{~g} / \mathrm{ml}$ in $0.15 \mathrm{M} \mathrm{NaCl}$ containing $0.01 \%$ EDTA (pH 7.4). The infranatant was adjusted to $d 1.063 \mathrm{~g} / \mathrm{ml}$ by the addition of $\mathrm{NaCl}-\mathrm{NaBr}$ and subjected to ultracentrifugation in a 40.3 rotor at $39,000 \mathrm{rpm}$ for $20 \mathrm{~h}\left(15^{\circ} \mathrm{C}\right)$. LDL $(d 1.019-1.063 \mathrm{~g} / \mathrm{ml})$ was isolated by tube slicing $(\sim 1.5 \mathrm{ml})$ and dialyzed to $d 1.006 \mathrm{~g} / \mathrm{ml}$.

Specific activities of $V L D L-B, I D L-B$, and $L D L-B$. Specific activities of VLDL-B and IDL-B were determined according to by Le et al. (19). $1 \mathrm{ml}$ of isolated lipoproteins (0.4-1.0 $\mathrm{mg}$ of protein) was delipidated using acetone and then isopropranol. The supernatant from the VLDL extraction was carefully collected for analyses of VLDL-TG specific activity. $9 \mathrm{M}$ tetramethylurea (TMU) was added, and the samples were allowed to stand at room temperature overnight. On the following morning, $1 \mathrm{ml}$ of water was added, the samples centrifuged and the supernatant recovered. The apo B pellet was then washed with $9 \mathrm{~N}$ TMU and finally with water and evaporated to dryness. The apo B pellet was resolubilized in $1 \mathrm{M} \mathrm{NaOH}(0.5 \mathrm{ml}$ for VLDL, $0.25 \mathrm{ml}$ for IDL and $1.0 \mathrm{ml}$ for $\mathrm{LDL}$ ), sonicating the samples at $37^{\circ} \mathrm{C}$ for $1-3 \mathrm{~d}$. An aliquot of the resolubilized apo B pellet was counted for ${ }^{131} I$ and ${ }^{125}$ I radioactivity in a Packard model $\mathbf{5 8 2 0}$ automatic gamma scintillation spectrometer (Packard Instrument Co., Inc., Downers Grove, IL) and the apo B protein was determined by the method of Lowry et al. (20). The value obtained by this procedure corresponded closely to the specific activity estimated by the difference between total mass and radioactivity and the soluble mass and radioactivity after TMU precipitation.

For LDL specific activity, the total radioactivity and mass on an isolated fraction of LDL were determined. Apo B in this fraction was precipitated, and counts and peptide mass were determined on the supernatant. Apo B specific activity was then calculated by difference. $2 \mathrm{ml}$ sample of plasma was also counted to determine ${ }^{125} \mathrm{I}$ plasma activity.

$V L D L-T G$ specific activity. The acetone and isopropanol extracts of VLDL samples were pooled for measurement of VLDL-TG specific activity. These extracts were evaporated to dryness with nitrogen at $60^{\circ} \mathrm{C}$, and each dried residue was dissolved in $10 \mathrm{ml}$ of isopropanol. Each sample was then treated with zeolite and isopropanol, and the supernatants were collected and transferred quantitatively into scintillation vials. These isopropanol extracts were dried under nitrogen at $60^{\circ} \mathrm{C}$, and $10 \mathrm{ml}$ of liquid flour was added to each vial. The samples were counted in a liquid scintillation counter (Mark II, Searle Radiographics Inc., Des Plaines, IL) for ${ }^{3} \mathrm{H}$-radioactivity after allowing enough time (usually over $2 \mathrm{mo}$ ) for complete ${ }^{131}$ I decay. Concentrations of VLDL-TG were measured on each sample after isolation by ultracentrifugation.

Concentrations of lipoprotein lipid and apo B. The concentration of VLDL-B was determined as follows. The concentration of VLDLTG was determined for each sample isolated by ultracentrifugation during the VLDL turnover study. The average concentration for the 48-h period was estimated using the correction for recovery described previously (21). The lipids in IDL, LDL, and HDL were determined on each fraction isolated by successive ultracentrifugations. Percent recovery was estimated by comparing total cholesterol with the sum of cholesterol in all fractions. The final concentration of cholesterol and TG in each fraction was calculated by applying the same percent recovery to each.

For all VLDL samples, VLDL-B was determined as the difference between total protein and the TMU-soluble protein (19). VLDL-B concentration was estimated by multiplying the corrected VLDL-TG concentration by the VLDL-B/TG ratio. Likewise, the IDL-B level was obtained by multiplying the IDL-B/TG ratio by the IDL-TG level. The concentration of LDL-B used was that obtained during the VLDLB turnover study. On the isolated LDL $(d 1.019-1.063 \mathrm{~g} / \mathrm{ml})$, both LDL-cholesterol and LDL-B were measured; the apo B mass was calculated as the difference between total protein and TMU-soluble 
proteins (19). The concentration of LDL-B was obtained by multiplying the corrected LDL-cholesterol by the LDL-B/TG ratio.

The pool size of apo B in each lipoprotein fraction was estimated as the product of the concentration times plasma volume. The plasma volume was determined by isotope dilution of labeled LDL. The concentration of injected label at 0 time was that obtained by extrapolation of to 0 of radioactivity in samples obtained over the first 20 min. This estimated plasma volume was used to determine plasma pool sizes of VLDL, IDL, and LDL.

\section{Kinetic analysis}

The data obtained in this study included concentrations of lipids (cholesterol and TG) and apo B in each lipoprotein fraction (VLDL, IDL, and LDL), specific activities of apo B in VLDL, IDL, and LDL, and urinary to plasma ratios for ${ }^{125} \mathrm{I}(22)$. Multicompartmental analysis was carried out using the model shown in Fig. 7 of the preceding article (6). This model allows the calculation of fractional catabolic rates (FCRs) and transport rates for VLDL-TG, total VLDL-B, IDL$B$, and LDL-B. The fractions of VLDL-B passing through the chaindelipidation pathway and slowly catabolized compartment were determined, as were fractions of apo B transport through IDL-B. The proportion of VLDL-B removed directly from the circulation before conversion to IDL was estimated, as was the "direct" input of LDL. Finally, total input of apo B with lipoproteins was calculated from the model hypothesized in Fig. 10 of reference 6.

The results for transport rates are expressed as milligram/day, milligram/kilogram-day, and milligram/kilogram of IW-day for reasons described previously (18). Statistical comparison of data among the groups was made with the Student's two-tailed $t$ test.

\section{Results}

Concentrations of plasma cholesterol and TG, and cholesterol in LDL and HDL, during the VLDL turnover study are presented in Table II. There were no significant differences between mean values for normal subjects and either of the other two groups. However, one obese patient (no. 8) and one patient with CHD (no. 14) had abnormally high levels of LDL-cholesterol.

Data on VLDL-TG kinetics are given in Table III. Mean concentrations of VLDL-TG among the three groups were not significantly different. However, transport rates of VLDL-TG in the obese group, expressed as grams/day and milligrams/ kilogram of IW-day, were significantly higher than normal. In contrast, transport rates in the coronary group were not abnormally high.

Concentrations of VLDL-B were above normal in both obese and CHD patients (Table IV). The FCRs of plasma VLDL-B, however, were not different among the groups. In obese patients, transport rates of VLDL-B were numerically but not statistically significantly higher than normal when expressed in absolute rates or per kilogram; they were nonetheless significantly higher when expressed per kilogram of IW. In CHD patients, transport rates of VLDL-B were higher than normal regardless of how data were expressed. The mean plasma VLDL-TG/VLDL-B ratio in normal subjects was $11.0 \pm 0.9$; this value was not significantly different from that of obese patients $(9.6 \pm 0.4)$, but it was significantly greater than that of $C H D$ patients $(6.9 \pm 0.3, P<0.005)$. These differences in ratios reflect the finding that abnormally high transport rates were noted for both VLDL-TG and VLDL-B in obese subjects but only for VLDL-B, and not VLDL-TG, in CHD patients. These differences also are reflected in the ratios of transport rates for VLDL-TG and VLDL-apo B.

Data for IDL-B and LDL-B metabolism are presented in Tables V and VI. Plasma concentrations of IDL-B were similar

Table III. VLDL-TG Kinetics

\begin{tabular}{|c|c|c|c|c|c|}
\hline \multirow[b]{2}{*}{ Patients } & \multicolumn{2}{|l|}{ VLDL-TG } & \multirow{2}{*}{$\begin{array}{l}\text { VLDL-TG } \\
\text { transport }\end{array}$} & \multirow{2}{*}{$\begin{array}{l}\text { VLDL-TG } \\
\text { transport }\end{array}$} & \multirow{2}{*}{$\begin{array}{l}\text { VLDL-TG } \\
\text { transport }\end{array}$} \\
\hline & Concentration & FCR & & & \\
\hline & $m g / d l$ & pools/d & $g / d$ & $m g / k g-d$ & $m g / k g I W-d$ \\
\hline \multicolumn{6}{|l|}{ Normal subjects } \\
\hline 1 & 96 & 4.6 & 16.1 & 206 & 236 \\
\hline 2 & 121 & 5.2 & 25.8 & 292 & 326 \\
\hline 3 & 146 & 5.2 & 25.0 & 312 & 362 \\
\hline 4 & 113 & 8.0 & 26.6 & 341 & 364 \\
\hline 5 & 185 & 6.0 & 31.9 & 409 & 456 \\
\hline Mean \pm SEM & $132 \pm 15$ & $5.8 \pm 0.6$ & $25.1 \pm 2.5$ & $306 \pm 32$ & $348 \pm 35$ \\
\hline \multicolumn{6}{|l|}{ Obese subjects } \\
\hline 6 & 199 & 4.1 & 33.4 & 309 & 398 \\
\hline 7 & 143 & 10.3 & 44.9 & 554 & 701 \\
\hline 8 & 192 & 6.0 & 30.6 & 431 & 600 \\
\hline 9 & 172 & 7.7 & 50.7 & 409 & 746 \\
\hline \multirow[t]{2}{*}{ Mean \pm SEM } & $177 \pm 13$ & $7.0 \pm 1.3$ & $39.9 \pm 4.7^{*}$ & $425 \pm 44$ & $611 \pm 77^{*}$ \\
\hline & & & $(P<0.05)$ & & $(P<0.02)$ \\
\hline \multicolumn{6}{|l|}{ CHD patients $\ddagger$} \\
\hline 10 & 169 & 5.5 & 26.3 & 398 & 438 \\
\hline 11 & 94 & 7.5 & 17.8 & 222 & 254 \\
\hline 12 & 199 & 2.5 & 15.2 & 217 & 238 \\
\hline 13 & 145 & 9.3 & 45.8 & 610 & 602 \\
\hline Mean \pm SEM & $152 \pm 22$ & $6.2 \pm 1.5$ & $26.3 \pm 6.9$ & $361 \pm 93$ & $383 \pm 85$ \\
\hline
\end{tabular}

* Significantly different from normal data at $P$ value shown. $¥$ Patient 14 was not studied. 
Table IV. VLDL-B Kinetics

\begin{tabular}{|c|c|c|c|c|c|c|}
\hline \multirow[b]{2}{*}{ Patients } & \multicolumn{2}{|l|}{ VLDL-B } & \multirow[b]{2}{*}{$\begin{array}{l}\text { VLDL-B } \\
\text { transport }\end{array}$} & \multirow[b]{2}{*}{$\begin{array}{l}\text { VLDL-B } \\
\text { transport }\end{array}$} & \multirow[b]{2}{*}{$\begin{array}{l}\text { VLDL-B } \\
\text { transport }\end{array}$} & \multirow{2}{*}{$\frac{\text { VLDL-TG }}{\text { VLDL-B }}$ transport ratio } \\
\hline & Concentration & FCR & & & & \\
\hline & $m g / d l$ & pools/d & $m g / d$ & $m g / k g-d$ & $m g / k g I W-d$ & \\
\hline \multicolumn{7}{|l|}{ Normal subjects } \\
\hline 1 & 8 & 3.5 & 1,043 & 13.4 & 15.4 & 15.4 \\
\hline 2 & 10 & 2.8 & 1,122 & 13.2 & 14.8 & 22.1 \\
\hline 3 & 15 & 2.6 & 1,317 & 16.5 & 19.1 & 18.9 \\
\hline 4 & 14 & 2.1 & 853 & 10.9 & 11.7 & 31.3 \\
\hline 5 & 14 & 1.7 & 665 & 8.5 & 9.5 & 48.1 \\
\hline Mean \pm SEM & $12 \pm 1$ & $2.5 \pm 0.3$ & $1,000 \pm 112$ & $12.5 \pm 1.3$ & $14.1 \pm 1.6$ & $27.2 \pm 5.8$ \\
\hline \multicolumn{7}{|l|}{ Obese subjects } \\
\hline 6 & 21 & 2.2 & 1,014 & 17.7 & 22.8 & 17.4 \\
\hline 7 & 17 & 3.0 & 1,568 & 19.4 & 24.5 & 28.6 \\
\hline 8 & 19 & 1.8 & 904 & 12.7 & 17.7 & 33.9 \\
\hline 9 & 17 & 3.3 & 2,183 & 17.5 & 32.1 & 23.2 \\
\hline \multirow[t]{2}{*}{ Mean \pm SEM } & $20 \pm 1^{*}$ & $2.6 \pm 0.3$ & $1,642 \pm 276$ & $16.8 \pm 1.4$ & $24.2 \pm 3.0^{*}$ & $25.8 \pm 3.5$ \\
\hline & \multicolumn{2}{|l|}{$(P<0.001)$} & & & \multicolumn{2}{|l|}{$(P<0.002)$} \\
\hline \multicolumn{7}{|l|}{ CHD patients } \\
\hline 10 & 22 & 2.3 & 1,432 & 21.7 & 23.9 & 18.3 \\
\hline 11 & 15 & 4.8 & 2,316 & 29.0 & 20.7 & 7.7 \\
\hline 12 & 28 & 1.7 & 1,447 & 20.7 & 22.6 & 10.5 \\
\hline 13 & 22 & 2.6 & 1,929 & 25.7 & 25.4 & 23.7 \\
\hline 14 & 16 & 2.9 & 1,321 & 17.6 & 20.3 & - \\
\hline \multirow[t]{2}{*}{ Mean \pm SEM } & $21 \pm 2^{*}$ & $2.9 \pm 1$ & $1,689 \pm 188^{*}$ & $22.9 \pm 2.0^{*}$ & $25.1 \pm 42.2^{*}$ & $15.0 \pm 3.6^{*}$ \\
\hline & \multicolumn{2}{|l|}{$(P<0.005)$} & $(P<0.02)$ & $(P<0.005)$ & $(P<0.005)$ & $(P<0.05)$ \\
\hline
\end{tabular}

* Significantly different from control at the $P$ value shown.

Table V. IDL-B Kinetics

\begin{tabular}{|c|c|c|c|c|c|}
\hline \multirow[b]{2}{*}{ Patients } & \multicolumn{2}{|l|}{ IDL-B } & \multirow{2}{*}{$\begin{array}{l}\text { IDL-B } \\
\text { transport }\end{array}$} & \multirow{2}{*}{$\begin{array}{l}\text { IDL-B } \\
\text { transport }\end{array}$} & \multirow{2}{*}{$\begin{array}{l}\text { IDL-B } \\
\text { transport }\end{array}$} \\
\hline & Concentration & FCR & & & \\
\hline & $m g / d l$ & pools/d & $m g / d$ & $m g / k g-d$ & $m g / k g I W-d$ \\
\hline \multicolumn{6}{|l|}{ Normal subjects } \\
\hline 1 & 0.7 & 3.1 & 80 & 1.0 & 1.2 \\
\hline 2 & 4.5 & 2.2 & 393 & 4.6 & 5.2 \\
\hline 3 & 2.0 & 1.5 & 100 & 1.3 & 1.4 \\
\hline 4 & 3.7 & 1.3 & 136 & 1.7 & 1.9 \\
\hline 5 & 1.7 & 1.3 & 64 & 0.8 & 1.1 \\
\hline Mean \pm SEM & $2.5 \pm 0.7$ & $1.9 \pm 0.3$ & $155 \pm 56$ & $1.9 \pm 0.6$ & $2.0 \pm 0.7$ \\
\hline \multicolumn{6}{|l|}{ Obese subjects } \\
\hline 6 & 1.7 & 1.3 & 73 & 0.7 & 0.9 \\
\hline 7 & 1.2 & 1.5 & 74 & 0.9 & 1.2 \\
\hline 8 & 4.7 & 1.5 & 186 & 2.6 & 3.6 \\
\hline 9 & 2.2 & 2.7 & 227 & 1.8 & 3.3 \\
\hline Mean \pm SEM & $2.5 \pm 0.8$ & $1.8 \pm 0.3$ & $140 \pm 39$ & $1.5 \pm 0.4$ & $2.3 \pm 0.6$ \\
\hline \multicolumn{6}{|l|}{ CHD patients } \\
\hline 10 & 4.1 & 1.8 & 207 & 3.1 & 3.5 \\
\hline 11 & 4.3 & 3.5 & 483 & 6.0 & 6.9 \\
\hline 12 & 2.7 & 1.5 & 125 & 1.8 & 2.0 \\
\hline 13 & 3.6 & 2.2 & 270 & 3.6 & 3.6 \\
\hline 14 & 3.4 & 2.9 & 193 & 2.6 & 3.0 \\
\hline Mean \pm SEM & $3.6 \pm 0.3$ & $2.4 \pm 0.4$ & $256 \pm 61$ & $3.4 \pm 0.7$ & $3.8 \pm 0.8$ \\
\hline
\end{tabular}




\begin{tabular}{|c|c|c|c|c|c|}
\hline \multirow[b]{2}{*}{ Patients } & \multicolumn{2}{|l|}{ LDL-B } & \multirow{2}{*}{$\begin{array}{l}\text { LDL-B } \\
\text { transport }\end{array}$} & \multirow{2}{*}{$\begin{array}{l}\text { LDL-B } \\
\text { transport }\end{array}$} & \multirow{2}{*}{$\begin{array}{l}\text { LDL-B } \\
\text { transport }\end{array}$} \\
\hline & Concentration & FCR & & & \\
\hline & $m g / d l$ & pools/d & $m g / d$ & $m g / k g-d$ & $m g / k g I W-d$ \\
\hline \multicolumn{6}{|l|}{ Normal subjects } \\
\hline 1 & 63 & 0.36 & 832 & 10.7 & 12.2 \\
\hline 2 & 74 & 0.38 & 1,116 & 13.1 & 14.6 \\
\hline 3 & 94 & 0.36 & 1,140 & 14.3 & 16.5 \\
\hline 4 & 105 & 0.31 & 954 & 12.2 & 13.0 \\
\hline 5 & 107 & 0.38 & 1,171 & 15.0 & 16.7 \\
\hline Mean \pm SEM & $87 \pm 9$ & $0.36 \pm 0.01$ & $1,043 \pm 64$ & $13.1 \pm 0.8$ & $14.6 \pm 0.9$ \\
\hline \multicolumn{6}{|l|}{ Obese subjects } \\
\hline 6 & 74 & 0.41 & 1,232 & 11.4 & 14.7 \\
\hline 7 & 99 & 0.29 & 869 & 10.7 & 13.6 \\
\hline 8 & 133 & 0.29 & 1,018 & 14.3 & 20.0 \\
\hline 9 & 105 & 0.36 & 1,444 & 11.6 & 21.2 \\
\hline Mean \pm SEM & $103 \pm 12$ & $0.34 \pm 0.03$ & $1,140 \pm 109$ & $12.0 \pm 0.7$ & $17.3 \pm 1.6$ \\
\hline \multicolumn{6}{|l|}{ CHD patients } \\
\hline 10 & 112 & 0.35 & 1,102 & 16.7 & 18.4 \\
\hline 11 & 87 & 0.43 & 1,202 & 15.0 & 17.2 \\
\hline 12 & 94 & 0.46 & 1,343 & 19.2 & 21.0 \\
\hline 13 & 80 & 0.53 & 1,448 & 19.3 & 19.1 \\
\hline 14 & 134 & 0.26 & 989 & 13.4 & 15.2 \\
\hline Mean \pm SEM & $101 \pm 10$ & $0.41 \pm 0.04$ & $1,217 \pm 82$ & $\begin{array}{l}16.7 \pm 0.4^{*} \\
(P<0.005)\end{array}$ & $\begin{array}{l}18.2 \pm 0.4^{*} \\
(P<0.01)\end{array}$ \\
\hline
\end{tabular}

* Significantly different from normal at the $P$ value shown.

for the three groups, and they were only $12-20 \%$ of those of VLDL-B. Turnover rates of IDL-B averaged about two pools per day which were somewhat slower than turnover of VLDLB, but much greater than turnover of LDL-B (Table VI). In none of the patients did transport rates of IDL-B through the plasma compartment equal the LDL-B transport.

Concentrations of LDL-B were similar on the average in the three groups, although the two patients (nos. 8 and 14), who had elevated plasma LDL-C, also had relatively high levels of LDL-B. FCRs of LDL-B in normal subjects ranged from 0.31 to 0.38 pools/day, and they were not significantly different from the group means of either obese or $\mathrm{CHD}$ patients. However, in three patients with CHD (nos. 11, 12, and 13), FCRs were greater than 0.43 pools/day. The two patients with abnormally high LDL-B levels (nos. 8 and 14) had relatively low FCRs. Two obese patients (nos. 8 and 9) had elevated transport rates of LDL-B (when data were expressed per kilogram of IW), but the other two (nos. 6 and 7) did not; transport rates for the whole group were not significantly different than normal. In contrast, patients with CHD had elevated rates of LDL-B transport whether data were normalized per kilogram or kilogram of IW.

For the determination of the fate of all apo B entering the system, transport rates and proportions of all pathways were computed on the basis of the model hypothesized in Fig. 10 of the preceding article (6). Results are presented in Fig. 7. Total input rates of apo B $\left(\rightarrow V_{0}\right)$, expressed as milligram/day, were not significantly higher than normal in either obese or CHD patients; nonetheless, input rates were higher than normal in obese patients when data were normalized to ideal weight, and rates were abnormally high in CHD patients by normalization per kilogram of absolute weight or IW. Transfers between compartments are expressed as a percentage of all apo B entering $V_{0}$. Most VLDL-B passed into the VLDL delipidation cascade $\left(V_{1 \mathrm{a}} \rightarrow V_{1 \mathrm{n}}\right)$. The proportion of VLDL-B converted to LDL through the delipidation chain $\left(V_{1 \mathrm{a}} \rightarrow\right.$ $V_{1 \mathrm{n}} \rightarrow$ LDL) was similar for normal, obese, and CHD patients $(41 \pm 4 \%, 44 \pm 11 \%$, and $33 \pm 10 \%$, respectively). In normal subjects, direct removal of VLDL-B $\left(V_{0} \rightarrow\right.$ out $+V_{1 \mathrm{n}} \rightarrow$ out $)$ averaged $27 \pm 7 \%$. Although the percentages removed directly were numerically higher in obese patients $(41 \pm 8 \%)$ and CHD patients $(51 \pm 9 \%)$, they were not significantly different from normal. For most subjects of all groups, $<5 \%$ of apo B passed through slowly catabolized VLDL $\left(V_{2}\right)$, whether $V_{2} \rightarrow$ out or $V_{2} \rightarrow$ LDL. In all but one subject, at least a portion of apo-B mass in $V_{0}$ was converted directly to $\mathrm{LDL}\left(V_{0} \rightarrow \mathrm{LDL}\right.$ or "direct" input of LDL). In normal subjects, "direct" input of LDL averaged $28 \pm 5 \%$ of total input of apo B, and this percentage was significantly higher than that for either obese or CHD patients $(10 \pm 3 \%$ and $15 \pm 1 \%$, respectively).

\section{Discussion}

The primary aim of this study was to generate data for the development of a comprehensive and integrated model to describe the kinetics of apo B-containing lipoproteins, as presented in the preceding article (6). A second purpose was to define and quantify pathways and compartments of these lipoproteins in normal subjects. For the latter purpose, tripleisotope studies were carried out in five normolipidemic men. 
A third objective was to examine the metabolism of apo B in types of patients previously shown in our laboratory to have normal plasma lipids but increased turnover of LDL-B, namely, patients with obesity (four patients) and a group of patients with CHD (five patients). Although the numbers of subjects in each group were relatively small, the subjects seem representative of their categories based on data obtained previously in our laboratory $(5,6)$. The parameters of lipoprotein kinetics determined in this investigation were generated by the multicompartmental analysis proposed in the preceding report (6); the validity of these parameters thus depends on the assumptions and limitations of this analysis.

Apo $B$ metabolism in normal subjects. The five normal subjects of the current study had levels of plasma total cholesterol and TG in the normal range. Their transport rates of VLDL-TG were similar to those of a larger group of normal subjects studied previously (23). For some reason, transport rates of LDL-B averaged $2-3 \mathrm{mg} / \mathrm{kg}-\mathrm{d}$ higher than previously found for comparable normal subjects from our laboratory (4, 5); nonetheless, in most respects, this difference was not enough to obscure the differences between normal subjects and the two abnormal groups. Our findings in the normal subjects furthermore allow us to examine certain questions about the normal physiology of lipoproteins containing apo B.

First, let us ask how much apo B normally enters plasma each day with newly secreted lipoproteins. In our normal subjects, the total input of apo B averaged $19.6 \pm 1.7 \mathrm{mg} / \mathrm{kg}-\mathrm{d}$
(Table VII). Unfortunately, nonisotopic methods are not available at the present time to verify this value. There is, however, another comparison of interest. Goldstein et al. (24) have postulated that, in patients with homozygous familial hypercholesterolemia (FH), all VLDL-B is converted to LDL-B because of lack of LDL receptors to remove VLDL remnants. If this is true, the transport of LDL-B in such patients should closely approximate total input of apo B in all apo B-containing lipoproteins. We therefore compared our results to those reported in the literature for transport of LDL-B in patients with homozygous FH (25-29). If we exclude very young patients with homozygous $\mathrm{FH}$, who frequently have extremely high transport rates of LDL-B $(25,26,30), 10$ older patients with this disease (ages 13-25 yr) have been reported to have a mean transport rate of LDL-B of $20.3 \pm 1.3 \mathrm{mg} / \mathrm{kg}-\mathrm{d}(25-29)$. It is of interest that this value corresponds closely to the average estimated for total input of apo B in our normal subjects.

Second, what fraction of VLDL-B is converted to LDL? Early reports suggested that VLDL-B is converted quantitatively to $\mathrm{LDL}$ in most normal subjects $(16,31-33)$. This claim, however, has been brought into question by more recent studies (33). The current data showed clearly that quantitative conversion of VLDL-B to LDL does not occur in most patients. In our normal subjects, $\sim 30 \%$ of VLDL-B was removed directly from the circulation. Most of the removal occurred from the apo B passing through the delipidation

Table VII. Total Apo B Transport

\begin{tabular}{|c|c|c|c|c|c|c|c|c|}
\hline \multirow[b]{2}{*}{ Subjects } & \multirow{2}{*}{$\begin{array}{l}\text { Total B } \\
\text { transport } \\
\left(\rightarrow V_{0}\right)^{*}\end{array}$} & \multirow{2}{*}{$\begin{array}{l}\text { Total B } \\
\text { transport } \\
\left(\rightarrow V_{0}\right)^{*}\end{array}$} & \multirow{2}{*}{$\begin{array}{l}\text { Total B } \\
\text { transport } \\
\left(\rightarrow V_{0}\right)^{*}\end{array}$} & \multirow{2}{*}{$\begin{array}{l}\text { VLDL-B in delipidation } \\
\text { chain converted to LDL } \\
\left(V_{10} \rightarrow V_{1} \rightarrow \mathrm{LDL}\right)\end{array}$} & \multirow{2}{*}{$\begin{array}{l}\text { Direct removal } \\
\text { of VLDL-B } \\
\left(V_{0} \text { and } V_{10} \rightarrow \text { out }\right)\end{array}$} & \multicolumn{2}{|c|}{$\begin{array}{l}\text { Fate of slowly } \\
\text { catabolized VLDL }\end{array}$} & \multirow{2}{*}{$\begin{array}{l}\text { "Direct" input } \\
\text { of LDL } \\
\left(V_{0} \rightarrow L D L\right)\end{array}$} \\
\hline & & & & & & $V_{2} \rightarrow$ out & $V_{2} \rightarrow \mathrm{LDL}$ & \\
\hline & $m g / d$ & $m g / k g-d$ & $m g / k g I W-d$ & $\%$ & $\%$ & $\%$ & $\%$ & $\%$ \\
\hline \multicolumn{9}{|l|}{ Normal subjects } \\
\hline 1 & 1,341 & 17.2 & 19.7 & 49 & 34 & 3 & 0 & 14 \\
\hline 2 & 1,800 & 21.2 & 23.7 & 28 & 35 & 3 & 0 & 34 \\
\hline 3 & 2,072 & 25.9 & 30.0 & 35 & 42 & 3 & $\mathbf{0}$ & 20 \\
\hline 4 & 1,312 & 16.8 & 18.0 & 47 & 24 & 3 & $\mathbf{0}$ & 26 \\
\hline 5 & 1,306 & 16.7 & 18.7 & 45 & 0 & 4 & 7 & 44 \\
\hline Mean \pm SEM & $1,566 \pm 157$ & $19.6 \pm 1.7$ & $22.0 \pm 1.8$ & $41 \pm 4$ & $27 \pm 7$ & $3 \pm 0.2$ & $1.4 \pm 1.4$ & $28 \pm 5$ \\
\hline \multicolumn{9}{|l|}{ Obese subjects } \\
\hline 6 & 1,943 & 18.1 & 23.1 & 55 & 35 & 1 & 8 & 1 \\
\hline 7 & 2,596 & 32.1 & 40.1 & 18 & 66 & 1 & 3 & 12 \\
\hline 8 & 1,602 & 22.6 & 31.4 & 35 & 34 & 3 & $\mathbf{0}$ & 28 \\
\hline 9 & 2,183 & 17.5 & 32.1 & 66 & 30 & 3 & 0 & 0 \\
\hline Mean \pm SEM & $2,081 \pm 209$ & $22.6 \pm 3.3$ & $\begin{array}{l}32 \pm 3.5 \ddagger \\
(P<0.05)\end{array}$ & $44 \pm 11$ & $41 \pm 8$ & $2 \pm 0.6$ & $3 \pm 8$ & $\begin{array}{l}10 \pm 3 \ddagger \\
(P<0.02)\end{array}$ \\
\hline \multicolumn{9}{|l|}{ CHD patients } \\
\hline 10 & 2,302 & 34.9 & 38.4 & 33 & 49 & 2 & $\mathbf{0}$ & 16 \\
\hline 11 & 4,968 & 62.1 & 70.9 & 9 & 77 & 1 & $\mathbf{0}$ & 13 \\
\hline 12 & 1,718 & 24.5 & 26.1 & 65 & 21 & 1 & 3 & 10 \\
\hline 13 & 2,769 & 34.4 & 36.4 & 36 & 47 & 1 & 1 & 15 \\
\hline 14 & 2,542 & 34.4 & 39.0 & 20 & 60 & 1 & 0 & 19 \\
\hline Mean \pm SEM & $2,860 \pm 554$ & $\begin{array}{l}38.1 \pm 6.3 \ddagger \\
(P<0.02)\end{array}$ & $\begin{array}{l}42.2 \pm 7.5 \ddagger \\
(P<0.02)\end{array}$ & $33 \pm 10$ & $51 \pm 9$ & $1.2 \pm 0.2$ & $2 \pm 0.5$ & $\begin{array}{l}15 \pm 1 \ddagger \\
(P<0.05)\end{array}$ \\
\hline
\end{tabular}

* Total transport was computed as the sum of VLDL-B transport plus "direct" input of LDL incremented by the percentage of direct removal from compartment $V_{0}$; see Fig. 10, reference 6. ‡ Significantly different from control at $P$ value shown. 
cascade $\left(V_{0} \rightarrow V_{1 \mathrm{n}}\right)$; direct removal from the slow compartment $\left(V_{2}\right)$ was only about $3 \%$. Only one patient (no. 5) appeared to have a near quantitative conversion of VLDL-B to LDL.

Third, what portion of LDL-B is derived from the "direct" input pathway? The current results demonstrated that some of the mass of apo B entering the LDL compartment of normal subjects is not traced by exogenously labled VLDL-B. In the preceding article (6), this untraced pathway was postulated to represent rapid catabolism of newly secreted VLDL, or possibly direct secretion of IDL. Untraced input of LDL-B was reported first in homozygous FH (28), but this route has been claimed more recently for other types of patients $(34$, 35). In our current study, the normal subjects had a higher "direct" input of LDL-B than the other two groups who had overproduction of VLDL-B (Table VII). The relatively low level of "direct" production of LDL-B in obese and coronary groups might have several causes. First, normal subjects could produce many small VLDL (or IDL) that are rapidly converted to LDL and thus appear as "direct" synthesis. On the other hand, patients with overproduction of VLDL might produce VLDL that are poor substrates for lipoprotein lipase, or excess VLDL might "overload" available lipase, either of which could interfere with rapid transformation of VLDL into LDL. The available data do not allow us to differentiate among these possibilities.

And finally, does all VLDL-B converted to LDL pass through the circulating pool of IDL $\left(I_{p}\right)$ ? In our normals, transport of apo B through plasma IDL-B averaged only $14 \%$ of LDL-B transport. This was true even though turnover of IDL-B averaged almost two pools per day. The low transport of apo B through IDL requires an explanation. One factor likely contributing to this low value is losses of IDL during preparative ultracentrifugation; the concentrations of IDL-B appeared to be rather low, and accurate assessment of transport rates depend on quantitative isolation of this fraction. Another possibility is that a portion of the mass of apo B converted from VLDL to LDL passes through a sequestered pool of IDL as postulated earlier (6). If so, it might never appear in the circulating pool of IDL. Resolution of the existence of this pool will require improved methodology for recovery of IDL, and studies must be devised to investigate IDL metabolism that independently examine the metabolism of this lipoprotein.

Apo B metabolism in obese Caucasians. We have reported previously that marked obesity is associated with increased transport of LDL-B (4). Excessive flux of LDL-B occurs even when concentrations of LDL cholesterol are not increased. What is the mechanism for this overproduction of LDL-B? Production rates of VLDL-TG clearly are enhanced in obese subjects (18), a finding that raised the possibility that production of VLDL-B also is increased which can explain the excessive input of LDL-B. In support of this concept, the following article (35) demonstrates clearly that markedly obese patients have an abnormally high input of VLDL-B. Likewise, in the current patients, who had only mild to moderate obesity, secretion rates of both VLDL-TG and VLDL-B were increased. These changes imply an increase in the number of VLDL particles entering plasma, a mechanism confirmed by the high input of total apo B in our obese patients.

What determines concentrations of VLDL and LDL in obese patients in whom secretion of VLDL particles is increased? Two factors seem important; these are the fraction of
VLDL-B converted to LDL and the FCR of LDL-B. The two most obese patients of the obese group (nos. 8 and 9) had relatively high secretion rates of VLDL-B, a normal fractional conversion of VLDL-B to LDL-B, and consequently high influx rates of LDL-B. Patient 9 compensated for a high input of LDL-B with a relatively high FCR for LDL; he thus maintained normal levels of LDL. Patient 8 , in contrast, had a relatively low FCR for LDL, and her high input of LDL-B resulted in hypercholesterolemia. Another patient (no. 7) had a normal input and normal concentrations of LDL-B despite overproduction of VLDL-B; he was protected from hypercholesterolemia in spite of having both overproduction of VLDL$B$ and a relatively low FCR of LDL because direct removal of VLDL-B also was high. Thus, the resulting concentrations of LDL in obese patients appear to be determined largely by the response to overproduction of VLDL (i.e., the percentage direct removal of VLDL and the rate of clearance of LDL). For reasons not determined, the "direct" input of LDL also was relatively low in obese patient.

Apo $B$ metabolism in patients with $C H D$. We likewise have shown previously that a subset of patients with premature CHD have increased transport rates of LDL-B even in the absence of hypercholesterolemia (5). Four of the five current patients with CHD also had normocholesterolemia; one patient (no. 14) had hypercholesterolemia, but he did not have tendon xanthomata or a family history suggestive of heterozygous FH. All patients in this group had relatively high transport rates of LDL-B. We therefore might ask about the mechanism responsible for an excessive input of LDL-B. Two possibilities can be considered: $(a)$ increased fractional conversion of VLDL-B to LDL, as seemingly occurs when LDL receptor activity is low (24), or (b) increased secretion of VLDL-B with a relatively normal fractional conversion of VLDL to LDL.

The current group of CHD patients clearly had increased secretion of VLDL-B. These patients had enhanced transport rates of VLDL-B even though the input of VLDL-TG was normal. They thus differed from our obese patients in whom secretion rates of both VLDL-TG and VLDL-B were high; the obese patients presumably secreted an increased number of normal VLDL in contrast to the CHD patients who apparently secreted an increased number of VLDL particles that were poor in $\mathrm{TG}$.

The current patients with CHD confirms that overproduction of VLDL-B can occur without hyperlipidemia. Still, hyperlipidemia sometimes occurs in patients of this type. An increased synthesis of VLDL-B has been postulated as the underlying metabolic defect in familial combined hyperlipidemia (36-38). We suggest that our patients, who also had overproduction of VLDL-B, had a similar if not identical metabolic defect. As suggested for obesity, an overproduction of lipoproteins on a primary basis theoretically might give rise to several different lipoprotein phenotypes. If the clearance capacity for lipoproteins is relatively high, concentrations will remain in the normal range, as seen in four of our patients with $\mathrm{CHD}$. On the other hand, if concomitant abnormalities in catabolism are present, even though they may be relatively mild, various forms of hyperlipidemia will result. A concomitant defect in clearance of TG-rich lipoproteins thus may cause hypertriglyceridemia; this mechanism has been reported previously for patients with familial combined hyperlipidemia (23). Furthermore, a decreased clearance capacity for LDL 
should cause a high concentration of LDL, as was noted in patient 14 who had both overproduction of VLDL-B and a low FCR of LDL-B.

The results should not be taken to mean that all patients with premature CHD have overproduction of VLDL-B; many of them probably do not (39). The question must be raised whether the current patients' medications (i.e., $\beta$-adrenergic blocking agents and diuretics) contributed to their abnormalities in apo B metabolism. This question is worthy of further investigation. Nonetheless, the observation remains that the current patients with CHD had overproduction of VLDL-B without excessive input of VLDL-TG, and this abnormality is in contrast to the combined overproduction of VLDL-B and VLDL-TG of obese patients (35). Thus, a dissociation of secretion rates of VLDL-B and VLDL-TG can occur, and our findings raise the possibility that this pattern of VLDL secretion is associated with enhanced risk for CHD.

\section{Acknowledgments}

The authors wish to express their appreciation to Marjorie Whelan, and others of the nursing and dietetic services of the Special Diagnostic and Treatment Unit, Veterans Administration Medical Center, San Diego, California for their assistance on this project. Excellent technical assistance was provided by Elizabeth Baker and Charles Maintainis.

The research of Dr. Y. Antero Kesäniemi was partly supported by Merrell-Dow Pharmaceuticals, Inc., Indianapolis, Indiana. Dr. Scott M. Grundy was a Medical Investigator of the Veterans Administration. This research was supported by the Veterans Administration and grants HL-14197 and HL-29252 from the National Institutes of Health.

\section{References}

1. Gotto, A. M., V. W. Brown, R. I. Levy, M. E. Birnbaumer, and D. S. Fredrickson. 1972. Evidence for the identity of the major apoprotein in low density and very low density lipoproteins in normal subjects and patients with familial hyperlipoproteinemia. J. Clin. Invest. 51:1486-1494.

2. Kane, A., D. A. Hardman, and H. E. Paulus. 1980. Heterogeneity of apolipoprotein B: isolation of a new species from human chylomicrons. Proc. Natl. Acad. Sci. USA. 77:2465-2469.

3. Goldstein, J. L., and M. S. Brown. 1974. Binding and degration of low density lipoproteins by cultured human fibroblast: comparison of cells from a normal subject and from a patient with homozygous familial hypercholesterolemia. J. Biol. Chem. 249:5153-5162.

4. Kesäniemi, Y. A., and S. M. Grundy. 1983. Increased low density lipoprotein production associated with obesity. Arteriosclerosis. 3:170-177.

5. Kesäniemi, Y. A., and S. M. Grundy. 1983. Overproduction of low density lipoproteins associated with coronary heart disease. Arteriosclerosis. 3:40-46.

6. Beltz, W. F., Y. A. Kesäniemi, B. V. Howard, and S. M Grundy. Development of an integrated model for analysis of kinetics of apolipoprotein B in plasma very low density lipoproteins, intermediate density lipoproteins, and low density lipoproteins. J. Clin. Invest. 76: 575-585.

7. Metropolitan Life Insurance Company Statistical Bulletin. 1959. Metropolitan Life Insurance Co., New York.

8. The Lipid Research Clinics Program Epidemiology Committee. 1979. Plasma lipid distributions in selected North American populations: the Lipid Research Clinics Program Prevalence Study. Circulation. 60: 427-439.

9. Heiss, G., I. Tamir, C. E. Davis, H. A. Tyroler, B. Rifkind, G. Schoenfield, D. Jacobs, and I. D. Frantz, Jr. 1980. Lipoprotein- cholesterol distributions in selected North American populations: the Lipid Research Clinics Program Prevalence Study. Circulation. 61: 302-315.

10. Grundy, S. M. 1975. Effects of polyunsaturated fats on lipid metabolism in patients with hypertriglyceridemia. J. Clin. Invest. 55: 269-282.

11. Block, W. D., K. J. Jarrett, and J. B. Levine. 1965. Use of a single color reagent to improve the automated determination of serum total cholesterol. In Automation in Analytical Chemistry. Mediad Inc., New York. 345-347.

12. Kessler, G., and H. Lederer. 1965. Fluorometric measurements of triglycerides. In Automation in Analytical Chemistry. Mediad Inc., New York. 341-344.

13. Lipid Research Clinics Program Manual of Laboratory Operations. 1974. Department of Health, Education and Welfare Publication, National Institutes of Health. 75-628.

14. Lindgren, F. T., L. C. Jensen, R. D. Wills, and N. K. Freeman. 1969. Flotation rates, molecular weights and hydrated densities of lowdensity lipoproteins. Lipids. 4:337-344.

15. McFarlane, A. S. 1958. Efficient trace-labelling of proteins with iodine. Nature (Lond.). 182:53.

16. Bilheimer, D. W., S. Eisenberg, and R. I. Levy. 1972. The metabolism of very low density lipoprotein proteins. I. Preliminary in vitro and in vivo observations. Biochim. Biophys. Acta. 260:212-221.

17. Folch, J., M. Lees, and G. H. Sloane Stanley. 1957. A simple method for the isolation and purification of total lipids from animal tissues. J. Biol. Chem. 226:497-509.

18. Grundy, S. M., H. Y. I. Mok, L. Zech, D. Steinberg, and M. Berman. 1979. Transport of very low density lipoprotein triglycerides in varying degrees of obesity and hypertriglyceridemia. J. Clin. Invest. 63:1274-1283.

19. Le, N. A., J. S. Melish, B. C. Roach, H. Ginsberg, and V. W. Brown. 1978. Direct measurement of apoprotein-B specific activity in ${ }^{125}$ I-labeled lipoproteins. J. Lipid. Res. 19:578-584.

20. Lowry, O. H., N. J. Rosebrough, A. L. Farr, and R. J. Randall. 1951. Protein measurement with the Folin phenol reagent. J. Biol. Chem. 193:265-275.

21. Zech, L. A., S. M. Grundy, D. Steinberg, and M. Berman. 1979. Kinetic model for production and metabolism of very low density lipoprotein triglycerides. Evidence for a slow production pathway and results for normolipidemic subjects. J. Clin. Invest. 63:1262-1273.

22. Kesäniemi, Y. A., and S. M. Grundy. 1982. Significance of low density lipoprotein production in the regulation of plasma cholesterol level in man. J. Clin. Invest. 70:13-27.

23. Beil, U., S. M. Grundy, J. R. Crouse, and L. Zech. 1982. Triglyceride and cholesterol metabolism in primary hypertriglyceridemia. Arteriosclerosis. 2:44-57.

24. Goldstein, J. L., T. Kita, and M. S. Brown. 1983. Defective lipoprotein receptors and arteriosclerosis. N. Engl. J. Med. 309:288296.

25. Bilheimer, D. W., N. J. Stone, and S. M. Grundy. 1979. Metabolic studies in familial hypercholesterolemia. Evidence for a gene-dosage effect in vivo. J. Clin. Invest. 64:524-533.

26. Bilheimer, D. W., J. L. Goldstein, S. M. Grundy, and M. S. Brown. 1975. Reduction in cholesterol and low density lipoprotein synthesis after portocaval shunt surgery in a patient with homozygous familial hypercholesterolemia. J. Clin. Invest. 56:1420-1430.

27. Shepherd, J., H. R. Slater, and C. J. Packard. 1982. Low density lipoprotein receptor activity in man. In Lipoprotein Kinetics and Modeling. M. Berman, S. M. Grundy, and B. V. Howard, editors. Academic Press, Inc., New York. 157-168.

28. Soutar, A. K., N. B. Myant, and G. R. Thompson. 1977. Simultaneous measurement of apolipoprotein B turnover in very lowand low-density lipoproteins in familial hypercholesterolemia. Atherosclerosis. 28:247-256.

29. Thompson, G. R., T. Spinks, A. Ranican, and N. B. Myant. 
1977. Nonsteady state studies of low-density-lipoprotein turnover in familial hypercholesterolemia. Clin. Sci. Mol. Med. 52:361-369.

30. Bilheimer, D. W., J. D. Goldstein, S. M. Grundy, T. E. Starzl, and M. S. Brown. 1984. Liver transplantation to provide low-density lipoprotein receptors and lower plasma cholesterol in a child with homozygous familial hypercholesterolemia. N. Engl. J. Med. 311: 1658-1664.

31. Eisenberg, S., D. W. Bilheimer, R. I. Levy, and F. T. Lindgren. 1973. On the metabolic conversion of human plasma very low density lipoprotein to low density lipoprotein. Biochim. Biophys. Acta. 326: 361-377.

32. Sigurdsson, G., A. Nicoll, and B. Lewis. 1975. Conversion of very low density lipoprotein to low density lipoprotein. A metabolic study of apolipoprotein B kinetics in human subjects. J. Clin. Invest. 56:1481-1490.

33. Reardon, M. F., N. H. Fidge, and P. J. Nestel. 1978. Catabolism of very low density lipoprotein B apoprotein in man. J. Clin. Invest. 61:850-860.

34. Janus, E. D., A. Nicoll, R. Wootton, P. R. Turner, P. J. Magill, and B. Lewis. 1980. Quantitative studies of very low density lipoprotein: conversion to low density lipoprotein in normal controls and primary hyperlipidaemic states and the role of direct secretion of low density lipoprotein in heterozygous familial hypercholesterolemia. Eur. J. Clin. Invest. 10:149-159.

35. Egusa, G., D. W. Brady, S. M. Grundy, and B. V. Howard. The influence of obesity on the metabolism of apolipoprotein B in humans. J. Clin. Invest. 76:596-603.

36. Janus, E. D., A. M. Nicoll, P. R. Turner, P. Magill, and B. Lewis. 1980. Kinetic bases of the primary hyperlipoproteinemias: studies of apolipoprotein B turnover in genetically defined subjects. Eur. J. Clin. Invest. 10:161-172.

37. Kissebah, A. H., S. Alfarei, and P. W. Adams. 1981. Integrated regulation of very low density lipoprotein triglycerides and apolipoprotein-B kinetics in man: normolipidemic subjects familial hypertriglyceridemias and familial combined hyperlipidemia. Metab. Clin. Exp. 30:856-968.

38. Chait, A., J. J. Albers, and J. D. Brunzell. 1980. Very low density lipoprotein overproduction in genetic forms of hypertriglyceridemia. Eur. J. Clin. Invest. 10:161-172.

39. Vega, G. L., W. F. Beltz, and S. M. Grundy. 1985. Low density lipoprotein metabolism in hypertriglyceridemic and normolipidemic patients with coronary heart disease. J. Lipid Res. 26:115-126. 